\title{
UM MÉTODO PARA ESTUDO E CONSTRUÇÃO DO CASO EM PSICOPATOLOGIA
}

Marta Regina de Leão D’Agord

Psicóloga.

Professora Doutora do Departamento de Psicanálise e

Psicopatologia da UFRGS, membro do Grupo de Trabalho da Anppep, Pesquisa em Psicanálise.

RESUMO: Na situação de supervisão acadêmica de estágio em psicopatologia, elaboramos um método para a redação do estudo e construção do caso. Esse método consiste em um roteiro do qual destacamos para análise os tópicos: 1) exame do estado mental e2) posição transferencial. 0 uso desse método vem mostrando que o tópico posição transferencial produz um testemunho escrito de uma implicação pessoal.

Palavras-chave: Estudo e construção do caso, psicopatologia, psicanálise, método.

ABSTRACT: A method for the study and construction of a case in psychopathology. In the situation of academic supervision of psychopathology training, we elaborated a method of writing the case study and construction. This method is based on a summary of topics, some of then are: 1) the mental state exam, and 2) the transference position, and the diagnostic hypothesis. This method's practice shows that the transference position topic stands out a written testimony of the personal implication.

Keywords: Case study and construction, psychopathology, psychoanalysis, method.

ste trabalho tem origem na atividade de supervisão acadêmica de estágio em Psicopatologia no curso de graduação em Psicologia. Tal experiência de supervisão acadêmica do estágio em psicopatologia está centrada na possibilidade de os alunos ressignificarem a experiência vivida junto aos pacientes.

Segundo o dicionário Houaiss, 'significação' éo ato ou efeito de significar; aponta para uma representação mental relacionada a uma forma lingüística, um sinal, um fato ou um gesto. Uma significação é um sentido ou significado que é dado a um signo, a um fato, etc.

Trabalhamos com a perspectiva de uma significação em processo, na temporalidade, isto é, um novo sentido dado a 
um fato pode aparecer algum tempo depois do fato ocorrido. Ou seja, acontecendo um fato ao qual é dado o significado 1 no tempo 1, no tempo 2, um novo sentido, ou um significado 2, será possível. Neste trabal ho, nos referimos a uma ressignificação no sentido de um novo sentido, ou como uma sucessão de novos sentidos ou significados possíveis. Essa experiência de dar novo significado a fatos e gestos será chamada 'ressignificação'.

A ressignificação da experiência é proposta na forma de um texto, o estudo e construção do caso. Com o objetivo de orientar esse processo, elaborou-se um roteiro ou sumário de tópicos. Este roteiro inclui, entre outros, os seguintes itens:

- Exame do estado mental: no qual são descritas as funções que se encontram alteradas no paciente: atenção, senso-percepção, memória, orientação, consciência, pensamento, linguagem, inteligência, afeto, conduta.

- Posição transferencial: no qual se descreve como o paciente se apresenta e em que lugar situa o estagiário em seu discurso; e como o estagiário se sente nesse lugar.

\section{DO EXAME À POSIÇÃO TRANSFERENCIAL}

0 exame do estado mental consiste em uma investigação de sinais e sintomas patológicos importantes para a formulação diagnóstica. As informações são coletadas a partir da entrevistas e observação.

No roteiro do estudo de caso, o exame do estado mental implica uma observação clínica, no entanto, a inclusão do tópico 'posição transferencial' supõe um trabal ho de elaboração da escuta clínica. 0 método proposto inclui, portanto, uma escuta da fala do paciente e uma observação e descrição de sintomas. Seria possível, em uma experiência de estágio em Psicopatologia, escutar a fala do sujeito do sintoma e observar o sintoma do paciente? Ao longo dos anos, nossos alunos nos mostraram que isso é possível.

Qual é a influência metodológica presente em psicopatologia quando se utiliza o exame do estado mental? Sem dúvida, a prática de estágio em psicopatologia origina-se de uma tradição psiquiátrica, ao nascer como prática de observação nas instituições psiquiátricas asilares e forenses. E a tradição psiquiátrica vem acompanhada do exame clínico, o exame do estado mental, chamado, por alguns, de exame das funções do ego.

Mas a prática do exame é anterior à psiquiatria, como nos revela a análise de Foucault (1975/2004):

“Todas as ciências, análises ou práticas com radical 'psico', têm seu lugar nessa troca histórica dos processos de indi vidual ização. 0 momento em que passamos de mecanismos histórico-rituais de formação da individualidade a mecanismos científico- 
disciplinares, em que o normal tomou o lugar do ancestral, e a medida o lugar do status, substituindo assim a individualidade do homem memorável pela do homem calculável, esse momento em que as ciências do homem se tornaram possíveis, é aquele em que foram postas em funcionamento uma nova tecnologia do poder e uma outra anatomia política do corpo." (p.161)

A observação e registro do comportamento do indivíduo, a medida comparativa que tem como referência a "norma" e os "desvios" acompanham as práticas do exame. Este está no centro dos processos que constituem o indivíduo como efeito e objeto de poder, como efeito e objeto de saber. A vigilância sobre o indivíduo considerado "desviante" inclui anotações escritas, formando uma rede que capta e fixa este indivíduo. Enfim, o exame, afirma Foucault (1975/2004), "coloca os indivíduos em um campo de vigilância" (p.157).

A crítica de Foucault às praticas de exame, seja clínico seja escolar, dirige-se, portanto, ao processo de se tomar o indivíduo como objeto. Sempre que al guém é tomado por objeto, perde seu lugar de sujeito, de participante ativo e autor de sua história. A formulação de uma teoria do indivíduo como sujeito é uma contribuição da teoria psicanalítica, na medida em que a hipótese do inconsciente supõe uma divisão do sujeito. Assim, no processo de escuta psicanalítica, o sujeito é escutado como autor, mesmo que dividido, isto é, mesmo que nada queira saber de sua participação, ativa ou passiva, na sua história de vida. A teoria psicanalítica não pretende esgotar outros sentidos compreendidos sob o conceito de sujeito. No entanto, propõe aos praticantes de ciências e disciplinas com radical 'psico' um novo ponto de vista. Se somos objetos ou vítimas, de alguma maneira compactuamos com isso. Mesmo que disso nada saibamos, ou não suportemos saber. Ora, esse ponto de vista transforma nosso modo de trabal har como praticantes de disciplinas com prefixo 'psico': pois não estamos mais observando um indivíduo, mas escutando um sujeito.

A tendência daquele que se inicia nas práticas 'psico' é de se inserir na instituição enquanto um ol har à procura dos desvios ou anomalias de comportamento. Este olhar é próprio ao "saber científico" que produz diagnósticos com base no exame do estado mental do paciente. Essa forma de olhar anuncia-se pela manifesta perplexidade nos casos em que o indivíduo observado, o sujeito ora internado na instituição, nada aparenta, do ponto de vista do comportamento, de bizarro ou desviante.

A escuta exige diacronia, isto é, exige escutar um dia depois do outro. 0 olhar é pontual. 0 olhar nos devolve aquilo que olhamos. Antes precisamos aprender a escutar, depois poderemos aprender a diagnosticar.

0 relato de Tafuri (2003) sobre seu estágio em Bonneuil testemunha uma aprendizagem que começa com a escuta: 
“O estagiário estava em Bonneuil para conviver com a criança, do modo dela, a partir da história de vida, da cultura e dos sentimentos trazidos pelo estagiário. Segundo Mannoni, a criança só teria chances de sair do estado de ensimesmamento e de alienação se tivesse a chance de conviver com pessoas que pudessem imaginar e se colocar na relação com ela, independente de qualquer prévio conhecimento da doença dela. (...) Na idéia original de Mannoni, o estagiário, ao estar livre do saber científico sobre a doença de uma determinada criança, poderia criar formas de estar com ela, a partir de um encontro pessoal. Assim, a criança teria a oportunidade de ser pensadae imaginada pelo outro, para além da doença." ( $p .49)$

0 testemunho acima relata uma forma de ruptura com as práticas de exame e revela, também, que essas práticas do exame podem já estar incorporadas na prática do estagiário. Ou seja, os praticantes 'psico', na medida em que estão identificados a um saber científico sobre a doença, tornam-se portadores de um olhar examinador. Seguindo Foucault, poderíamos agregar: se há um indivíduo portador de um olhar diagnosticador sobre outros indivíduos, tomados como objetos, este indivíduo está identificado ao olhar e saber científico do qual é portador e representante. Portanto, não seria este indivíduo um produto, um efeito deste saber? E não seria próprio, daquele que é produto ou efeito, não se implicar na sua tarefa?

Mas, ao propor que os estagiários escrevessem sobre a " posição transferencial", inseríamos uma implicação, um efeito de sujeito no ato de observação. A leitura da produção escrita dos estagiários referente a esse tópico levou-nos a concluir que a orientação para que escrevessem sobre a transferência, implicava cada um na sua experiência. 0 tópico da posição transferencial desafiava e era considerado momento difícil da construção e estudo do caso. Era nesse tópico que aparecia a redação em primeira pessoa.

Quando de sua descoberta dos fenômenos transferenciais, como lhe foi reveIado pela experiência de Breuer, Freud havia observado o paradoxal na implicação pessoal daquele que escuta. Suportar que a sua própria pessoa, aparentemente, esteja implicada na fala do paciente, sem se deixar implicar pessoalmente por essa aparência. Alguns anos mais tarde, Freud (1914) compara a transferência a um playground.

“Tornamos a compulsão inócua, e na verdade útil, concedendo-Ihe o direito de afirmar-se num campo definido. Admitimo-la à transferência como a um playground no qual Ihe é permitido expandir-se em liberdade quase completa e no qual se espera que nos apresente tudo no tocante a pulsões patogênicas, que se acha oculto na mente do paciente." (FREUD, 1914/ 1987, v. XII, p.201) 
Palavra e ação se complementam e se excluem. Este "tudo" que é permitido às pulsões (Trieben) ocorre dentro de um enquadramento: tudo falar, substituindo atos por palavras. A metáfora da transferência como um playground (Tummeplatz) permite situá-la como um lugar, lugar da palavra: discurso. E se Freud a subdividia em transferência positiva e negativa, era porque concebia a pulsão como se utilizando deste playground, ou seja, a pulsão como uma dimensão do sujeito dividido, e não o indivíduo.

Em nosso roteiro, é utilizada a expressão "posição transferencial", o que se aproximaria da idéia de transferência como lugar, e também da idéia de permutabilidade ou mudança de lugar, pois uma posição pode não ser definitiva, mas momentânea. Nesse tópico, apresenta-se, ainda, a seguinte orientação para 0 estudo da posição transferencial: "escreva como o paciente se apresenta e em que lugar situa o estagiário em seu discurso e como o estagiário se sente nesse lugar". Eis duas acepções de transferência: uma que se refere ao discurso e outra que se refere a sentimentos. A primeira orientação, "em que lugar o paciente situa 0 estagiário em seu discurso" pode ser incluída na categoria de transferência simbólica, e a segunda, "como o estagiário se sente", na categoria de transferência que chamaremos 'imaginária'.

A transferência imaginária resulta da consideração aos sentimentos, e estes são recíprocos. Portanto, há relação dual e simétrica entre terapeuta e paciente sempre que se toma a palavra como portadora de sentimentos, pois os afetos (emoções e sentimentos) são recíprocos. É no contexto da transferência imaginária, como relação dual, que surge a contra-tranfferência, chancelando uma simetria e reciprocidade entre terapeuta e paciente, como dois indivíduos. Já a transferência simbólica é a relação sujeito a sujeito quando se instala a palavra como terceiro. Para situar a transferência simbólica, é preciso, portanto, considerar o discurso. É neste sentido que Lacan (1953-1954/ 1979) resgata o emprego da palavra 'transferência', por Freud, na obra A interpretação dos sonhos:

"O material significante, quer seja fonemático, hieroglífico, etc. é constituído de formas destituídas do seu próprio sentido e retomadas numa organização nova através da qual um outro sentido encontra como se exprimir. É exatamente a isso que Freud chama Ü beträgung, transferência." ( $p .278)$

A transferência, tomada em seu sentido simbólico, situa o sujeito que fala e, ao mesmo tempo, seu destinatário. Ora, é preciso um método para acessar essa forma de transferência, isto é, um método que considere as muitas funções que uma palavra sustenta, como observou Lacan (1953-1954/ 1979): 
"A palavra não tem nunca um único sentido, o termo, um único emprego. Toda palavra tem sempre um mais-além, sustenta muitas funções, envolve muitos sentidos. Atrás do que diz um discurso, há o que ele quer dizer e, atrás do que quer dizer, há ainda um outro querer-dizer, e nada será nunca esgotado." ( p.275)

Três anos antes, em “Intervenção sobre a transferência” , Lacan (1951/ 1998) precisara essa função da palavra dirigida ao outro:

“Trata-se de posições discursivas e funções dessas posições: a transferência situaria a posição subjetiva daquele que enuncia, e todo objeto de um tal discurso nada mais seria do que uma função dessa posição." (1951/ 1998, p.217)

Assim, se o fenômeno transferencial já está dado, consi derálo como transferência imaginária ou simbólica seria uma questão de escuta. Ou seja, a transferência é tomada imaginária ou simbolicamente por aquele que é dela o objeto ou a testemunha. Assim, a questão é como escutar o discurso do paciente.

Em primeiro lugar, é necessário estabelecer a distinção entre o sujeito enquanto eu, o falante, e o sujeito do inconsciente, que não fala, mas que remete o falante a um significante que o representa sem que ele, o falante, possa ter o controle sobre os efeitos do encadeamento de significantes. As formações do inconsciente são expressão da divisão entre o sujeito do enunciado, o sujeito gramatical que raciocina, mas não pensa, e o sujeito da enunciação, que pensa, mas não raciocina. Em uma fala, trata-se da relação do falante ao tesouro de significantes, relação que Lacan denominou relação ao campo do Outro (Autre). 0 campo do Outro pode ser definido como a alteridade fundamental que estrutura, por sua presença simbólica, através da língua, as relações subjetivas e intersubjetivas (de identificação, de filiação) .

\section{ESCUTAR COM OLHOS E OUVIDOS}

O desafio de nosso método de estudo e construção do caso em psicopatologia é fundamentar a escuta do psicopatológico como abertura para a escuta das séries significantes, assim como para a formação de imagens a partir dessa escuta. E para fundamentar um método de escuta da fala dos pacientes como um discurso situando aquele que enuncia e aquele que escuta, é preciso considerar a fala. Assim, a escuta nos levou para o terreno da linguagem, trajeto que já havia sido percorrido por Lacan, justamente para delimitar a transferência simbólica e para apontar para a escuta do encadeamento de significantes. Nesse caminho, Lacan encontrou os mitemas de Lévi-Strauss (1955/ 1966) e as linhas semânticas do discurso de Jakobson (1975).

Em A estrutura dos mitos, Srauss (1955/ 1966) analisa a estrutura do mito a partir de uma comparação com a estrutura da linguagem. Assim como, na estrutura da 
língua, é possível isolar unidades constitutivas que diferem entre si pelo grau de complexidade, no mito encontram-se grandes unidades constitutivas, os mitemas, que se situam em um nível mais elevado que os fonemas, morfemas e semantemas. Para reconhecer e isolar os mitemas, Lévi-Strauss propõe a análise estrutural guiando-se pelos princípios que servem de base à análise estrutural sob todas as suas formas. Esses princípios são os seguintes: a economia de explicação, unidade de solução, possibilidade de reconstituir o conjunto a partir de um fragmento e de prever os desenvol vimentos ulteriores a partir de dados atuais.

Procedendo assim, o antropólogo francês descobriu que, no mito, cada grande unidade constitutiva tem a natureza de uma relação; e que não se trata de uma relação isolada, mas feixes de relações, e que é somente sob a forma de combinações de tais feixes que as unidades constitutivas adquirem uma função significante. É no nível da oração, portanto, que o autor proporá a análise do mito. E é aí que se encontra a sua aproximação com a investigação lingüística de Jakobson.

0 mito é narrado diacronicamente (e Lévi-Strauss ilustra a diacronia pela linearidade do discurso), mas é possível proceder a uma leitura sincrônica (representando, em colunas, um traço comum que se trata de evidenciar). As colunas ( verticais) representariam feixes de relações afastados no tempo, mas aproximados pela presença de traços comuns.

Para Jakobson (1975), o desenvolvimento de um discurso pode ocorrer segundo duas linhas semânticas diferentes: um tema pode levar a outro, quer por similaridade, quer por contigüidade.

"O mais acertado seria talvez falar de processo metafórico no primeiro caso, e de processo metonímico no segundo, de vez que eles encontram sua expressão mais condensada na metáfora e na metonímia respectivamente (...) Manipulando esses dois tipos de conexão (similaridade e contigüidade) em seus dois aspectos (posicional e semântico) - por seleção, combinação e hierarquização - um indivíduo revela seu estilo pessoal, seus gostos e preferências verbais." (1975, p.55-56)

A idéia de combinação e seleção das palavras na fala inspirou Lacan a empregar o conceito de 'cadeia significante'. É na linearidade da cadeia significante que o sentido insiste, mas nenhum dos elementos da cadeia consiste na significação do que ele é capaz nesse mesmo momento. “Impõe-se, portanto, escreveu Lacan (1957/ 1998, p.506-507)" a noção de um deslizamento incessante do significado sob o significante".

Enfim, Lacan (1960/ 1998) chegará à formulação de que “Um significante é aquilo que representa o sujeito para outro significante" (p.833). Eis uma interpretação deste famoso aforismo lacaniano. U m significante produz um sujeito para outro significante. Quando x fala para y: "tu és meu filho", o significante 
filho produziu um sujeito para outro significante, pai. Ou seja, um sujeito assujeitado, preso, identificado, agora, ao significante pai. Esse é um exemplo do que Lacan denominou 'fala plena'.

O sujeito do enunciado (o eu gramatical) e o sujeito da enunciação (não designado gramaticalmente): um sujeito (eu que fala) ao falar de si mesmo, sempre fala mais do que havia intencionado, comete um ato fal ho, por exemplo. No ato falho, o sujeito da

enunciação é efeito da relação de um significante em relação a outro significante. $O$ sujeito é efeito de sua fala. Na produção linguagera, na fala em associação livre, produz-se sujeito do inconsciente, um sujeito que, mesmo evanescente, como uma fagulha, está no lugar da verdade.

Vale lembrar a posição lacaniana de que o inconsciente não existiria sem linguagem. É por isso que as leis da linguagem interessam à escuta psicanalítica. Caso o sentido seja efeito dos deslizamentos metonímicos e metafóricos em uma cadeia de associações em um discurso. E este sentido pode ser um sintoma. Será, também, por uma cadeia de associações em um discurso (associações livres), que se poderá decompor, resolver edissolver esse sintoma, processo que poderemos chamar de 'desassociativo' ou de 'desassociação livre'.

É nos deslizamentos de sentido da fala em situação de tratamento que Lacan escuta a transferência. Enquanto que Fédida (1991) escuta o fenômeno transferencial como um sonho, como uma palavra que não comunica, mas situa. É neste sentido, de lugar e mudança de lugar, que a concepção freudiana de transferência manteria proximidade com o uso de transfert por Bernheim, no sentido de transporte, transmissão, tradução.

Para abordar a escuta da transferência, Fédida retorna à obra de Freud (1912/ 1987) com o objetivo de lembrar que a transferência deve ser escutada como se escuta um sonho:

"As reações que provocamos revelam, ao mesmo tempo, al gumas das características que viemos a conhecer a partir do estudo dos sonhos. Os impulsos inconscientes não desejam ser recordados da maneira pela qual o tratamento quer que 0 sejam, mas esforçam-se por reproduzir-se de acordo com a atemporalidade do inconsciente e sua capacidade de alucinação. Tal como acontece aos sonhos, o paciente encara os produtos do despertar de seus impulsos inconscientes como contemporâneos e reais; procura colocar suas paixões em ação sem levar em conta a situação real. 0 médico tenta compeli-lo a ajustar esses impulsos emocionais ao nexo do tratamento e da história de sua vida, a submetê-los à consideração intelectual e a compreendê-los à luz de seu valor psíquico. Esta luta entre o médico e o paciente, entre o intelecto e a vida instintual, entre a compreensão e a procura da ação, é travada, quase exclusivamente, nos fenômenos da transferência." (1912/ 1987, v. XII, p.143). 
Fédida (1991) propõe a escuta da palavra como evocação de imagens no psicanalista. U m exemplo desta escuta através da figuração é apresentado quando o autor aborda uma situação de análise de supervisão:

"De fato, durante as sessões, a analista havia constatado que, nos momentos em que o paciente encontrava-se mais fechado em si mesmo, seu silêncio, ou seu sono, podiam provocar nela imagens de um retorno autonutritivo por meio dos ruídos produzidos ao fungar ou engolir. (...) A capacidade da analista de receber essas impressões - em si restabelecendo uma circularidade elementar de trocas sensoriais vitais - permitindo que elas se colocassem em figuras e depois nomeando-as, inicialmente em silêncio e em seguida em voz alta junto ao paciente foi determinante para (re-) construir a situação psicanalítica." (1991, p.226)

A escuta figurativa não se restringe ao momento do tratamento, para Fédida (1996) essa forma de escuta é relevante durante a situação de supervisão ou de apresentação do caso. É nas palavras re-escutadas ao serem pronunciadas a colegas em situação de seminário clínico ou de supervisão, que Fédida (1991) localiza o processo que ele denomina 'construção do caso'.

A escuta psicanalítica pode, portanto, caracterizar-se tanto por escuta figurativa como por escuta do encadeamento dos significantes. Vamos nos reportar ao resultado reconstrutivo obtido por Freud a partir da escuta das associações de um paciente em relação a um sonho em História deuma neuroseinfantil ( 1918 [1914]/ 1987):

0 sonho relatado:

"Sonhei que era noite e que eu estava deitado na cama. De repente, a janela abriu-se sozinha e fiquei aterrorizado ao ver que alguns lobos brancos estavam sentados na grande nogueira em frente da janela. Havia seis ou sete deles. Os lobos eram muito brancos e pareciam-se mais com raposas ou cães pastores, pois tinham caudas grandes, como as raposas, e orelhas empinadas, como cães quando prestam atenção a algo. Com grande terror, evidentemente de ser comido pelos lobos, gritei e acordei." (1918[1914]/ 1987, v. XVII, p.45)

Como resultado da análise provisória, incluindo as associações do sonhador, Freud estabelece os fragmentos para uma primeira reconstrução:

U ma ocorrência real - datando de um período muito prematuro - olhar - imobilidade - problemas sexuais - castração - o pai - algo terível. (1918[1914]/ 1987, v. XVII, p.51).

Em um segundo momento, depois de novas associações do paciente, Freud obtém a uma explicação que ele considera exaustiva: 
“As etapas da transformação do material, 'cena primária - história do lobo - conto dos 'Sete Cabritinhos' refletem o progresso dos pensamentos do sonhador durante a construção do sonho: 'desejo de obter do pai satisfação sexual - a compreensão de que a castração erauma condição necessária paraisso - medo do pai'” . (1918[1914]/ 1987, v. XVII, p.60).

Essa construção freudiana em duas etapas ensina que o significado do que se escuta é revelado só-depois ( nachträglich), ${ }^{1}$ por isso a atenção daquele que escuta deve ser eqüiflutuante.

Assim, uma escuta do encadeamento dos significantesé atenção eqüiflutuante, aguardando que uma série se produza no só-depois (nachträglich), na diacronia de uma fala. Uma análise que assim se opere, consistiria, segundo Leclaire (1977), "essencialmente em apontar e pôr em evidência uma série de termos cuja insistência mais ou menos manifesta, sempre sensível ao ouvido atento, revela que eles são do inconsciente" (1977, p.91).

o psíquico é formado pela língua materna, ou melhor, dos traços e restos mnêmicos que constituem o psiquismo, memória inconsciente e virtual, pois possibilita que, de algumas combinações de significantes, formem-se novas relações. Mas é o sistema da língua que possi bilita a reestruturação das combinações escutadas (ou lidas) que não ficaram senão como restos mnêmicos. Esses restos, os monemas e fonemas, enquanto recalcados, "atraem" novos significantes, no sentido das possíveis ligações por condensação e deslocamento na língua do falante.

Na carta de 10 de março de 1898 a Fliess, Freud já observara que:

"Aquilo que é visto no período pré-histórico produz o sonho; o que é ouvido, as fantasias; 0 que é sexualmente experimentado produz as psiconeuroses... um desejo recente só leva a um sonho quando consegue ligar-se a algum material desse período pré-histórico." (FREUD apud MASSON, 1986, p.303)

A partir dessa passagem, Caon (1996) propôs um quiasma que sintetizasse o processo de escuta psicanalítica: "escuta psicanalítica dirigida pelo olhar psicanalítico e leitura (olhar) psicanalítica dirigida pela escuta psicanalítica" (1996, p.69).

Neste quiasma, a escuta figurativa de Fédida e a escuta do encadeamento de si gnificantes de Lacan se complementam. Da escuta figurativa, o qui asma guarda a importância do olhar, isto é, a formação de figuras ou imagens mentais a

1"Só-depois" éa tradução proposta por Magno ( 1983) paraa concepção freudiana denachträglich. A tradução francesa, après- coup, também costuma ser utilizada. 
partir da escuta da fala de um paciente; da escuta do encadeamento de significantes, o quiasma aponta o aspecto de leitura. Isto significa ler, através da escuta, significantes anteriores à formação da palavra como tal, os quais poderiam, pela escansão, por exemplo, dar lugar a novas palavras. De modo que seria preciso escutar o encadeamento, mas também os tropeços e interrupções dos monemas e fonemas.

\section{O PESSOAL NA PRÁTICA}

Mas era preciso retomar o nosso quiasma e considerar o que Fédida escrevia sobre as imagens que ressoam naquele que escuta e sobre a implicação pessoal na prática de escuta de pacientes. Para fundamentar esse aspecto de nosso método, vamos dialogar com a experiência do seminário sobre o traço do caso.

A implicação pessoal na escuta psicanalítica tem sido investigada sob a forma de traço do caso por Dumézil (1989) eTauber (1989). Em 1983, um pequeno grupo de psicanalistas oriundos da Escola Freudiana de Paris organizou um seminário clínico chamado Letrait du cas ( 0 traço do caso). Claude Dumézil (1989) relata que se tratava de um seminário clínico fechado com cerca de dez participantes, embora periodicamente existisse uma abertura a um público ampliado.

Este autor relata que tomou contato com a expressão trait du cas na quarta capa do número 1 de Scilicet na sua primeira edição (1968), em um pequeno texto de apresentação, no qual Lacan justificava o princípio do texto não assinado que caracterizava os artigos daquela publicação francesa. Esse princípio seria suscetível de dar "mais segurança para evocar o pessoal na prática e, especialmente, 0 traço do caso". 2

0 objetivo do seminário sobre o traço do caso, inspirado por essa frase de Lacan, era trabalhar a partir do pessoal na prática clínica, com tudo o que isso comportasse ao se assumir o risco da expressão oral ou escrita. De acordo com o relato de Dumézil (1989), os participantes que se expuseram no seminário observaram efeitos inesperados operados sobre a construção narrativa e conceitual nesta dupla mudança: deslocamento de lugar e passagem à escritura.

Dumézil explora a polissemia da palavra 'traço' e sua justaposição ao termo 'caso', que fazem desse composto um laço-significante cuja polivalência poderia se mostrar operante na sua própria equivocidade. Pois o caso não é mais o analisante, não é o tratamento, não é a observação nem a anamnese, e muito menos o analista. É um pouco de cada um. 0 traço faz ligação ou a rompe, como uma interpretação, um dito espirituoso. Ele faz ligação entre a história do sujeito e as estruturas em causa no tratamento. 0 traço une, mas também corta.

\footnotetext{
2"Plus de securité pour évoquer le per sonnel dans la pratiqueet notamment letrait du cas" in Scilicet, 1, quatrième de couverture, Paris: Seuil, 1968. Dumézil (1988) observa, em nota na página 8 de seu livro, que este texto não aparece mais nas edições posteriores de Scilicet.
} 
Durante esses seminários clínicos, Dumézil (1989) observou que, ao invés de levar a relatos exaustivos de tratamentos, o traço do caso é "um virar do avesso" (retournement), uma palavra do analisante ou do analista, um acting out, um momento de suspensão na repetição que abre a resistência egóica do paciente vinculada ao sintoma e a resistência correlativa do analista. Segundo Dumézil (1989),

"É esse liame, temporariamente operatório, do desejo do paciente ao desejo do analista que faz sobressair o traço do caso, ao menos sua ficção, na medida em que a ficção remeteria à falta, à castração, à barra significante." (1989, p.30, tradução minha)

Dumézil (1989) também observa que "o traço remete ao traço unário, pois este é o ponto inicial de onde se produz a incidência do significante no desenvolvimento" ( p.30). 0 autor relata que a maior parte dos fragmentos clínicos de análise relatados naquele seminário concerniam massivamente aos temas da castração sob todas as suas formas, da angústia aos fantasmas, à passagem ao ato, ao infanticídio.

A experiência do seminário do traço do caso é marcante pela leitura do relato clínico durante o seminário. Esse fato produzia, segundo nos relataTauber (1989), um deslocamento de lugar: do oral ao escrito. 0 fato de ler um texto em um seminário clínico incitava a centrar o estudo sobre o modo como funcionava a relação analítica e não sobre o conteúdo das falas do paciente. Tauber (1989) nos remete a um exemplo de traço do caso no texto "La Ferule" (A palmatória) de Octave Mannoni.Trata-se de um texto clínico no qual Mannoni (1982) relata o que Ihe ocorreu quando do tratamento de uma paciente que por várias sessões apresentava uma fala que parecia preparada, mas que, repentinamente, levantava as pernas e gritava um pal avrão. Ocorreu, a Mannoni, uma série de imagens provenientes da leitura de textos biográficos mas também de sua história pessoal nas quais estavam em jogo diversas defesas contra o sentimento de vergonha. Mannoni (1982) relata: "a interpretação que guardei para mim se enuncia simplesmente assim: deve ser a vergonha, me veio no modo de uma hipótese" (1982, p.77, tradução minha).

Mannoni não entende a sua interpretação como uma hipótese, mas como um 'se deixar levar' pelos próprios pensamentos durante a escuta e observação da paciente. Esse processo vivo, criativo e singular, pelo qual uma interpretação vem a um psicanalista é próprio da construção do caso.

\section{A ESCUTA, A TRANSFERÊNCIA E A ESTRUTURA}

É preciso, antes de concluir, considerar que a experiência de estágio realizada pelos alunos acontece em instituições de atendimento a sujeitos estruturados psicoticamente. Isso exige algumas precisões quanto aos fenômenos transferenciais e 
a estrutura clínica da psicose. Um diagnóstico diferencial estrutural tomaria o relato biográfico do paciente local izando as respostas que o sujeito teria elaborado para as perguntas sobre filiação, paternidade, sexo e morte que dão forma ao processo edípico, isto é, o processo que envolve suportar a castração do Outro que se imagina tudo poder e de tudo gozar.

Essa correspondência é sintetizada por Quinet (2001), considerando as formas de negação da castração:

"Um tipo de negação nega o elemento mas o conserva, manifestando-se de dois modos: no recalque (Verdrängung) do neurótico, nega conservando o elemento no inconsciente, eno desmentido (Veleugnung) do perverso, nega conservando-o no fetiche. A foraclusão (Verwerfung) do psicótico é um modo de negação que não deixa rastro ou vestígio algum; ele não conserva, arrasa." (2001, p.76)

A Verwerfung éa rejeição de um significante primordial. Este significante é dado primitivamente, mas, afirma Lacan (1955-1956/ 1985), "ele não énada enquanto o sujeito não o faz entrar em sua história" (p.180). Para tal é preciso que um significante seja substituído por outro.

Na "Proposição de 9 de outubro de 1967", Lacan (2003) retomará: “o sujeito suposto saber é, para nós, o eixo a partir do qual se articula tudo o que acontece com a transferência" ( p.253). U m sujeito suposto, para Lacan, é um significante introduzido no discurso do psicanalisante. U m sujeito suposto saber corresponde à transferência imaginária, na qual um saber é suposto imaginariamente no analista, e 0 amor de transferência é seu efeito. Mas será na transferência simbólica que Lacan (1998) situará a escuta do analista, da qual são paradigmáticas as inversões dialéticas de Freud no Caso Dora. A primeira das quais acontece quando ele se vê diante da pergunta:

“Esses fatos estão aí, dizem respeito à realidade, e não a mim mesma. 0 que o senhor quer mudar nisso aí? Ao que Freud responde através de uma primeira inversão dialética (...): "Veja", ele diz a Dora, "qual é a sua parte na desordem de que você se queixa'." (1951/ 1998, p.218).

A escuta da transferência simbólica permite identificar lugares, posições, para além do imaginário, para além do sujeito suposto saber. E essa intervenção de Freud poderia ser interpretada no sentido de indicar o lugar da verdade para além do discurso.

Mas uma rejeição do significante primordial, uma inércia da simbolização, não impediria a formação de um sujeito suposto saber? No caso da psicose, 0 fenômeno transferencial apareceria como a busca de um testemunho de um 
saber, como observaAttié, "o paradoxo de necessitar de uma testemunha de sua certeza" (apud Forbes e Ferreti, 2005).

Quando o significante primordial foi rejeitado, ele se torna imóvel ou inerte porque não faz série com outros significantes. A consideração da impossibilidade de um gancho transferencial em casos de psicose, deve ser compreendida, portanto, no contexto da concepção de transferência como transposição, como troca de lugar no discurso. Não haveria gancho transferencial quando estivesse impedida a substituição de um significante por outro, isto é, não haveria condições de um significante representar um sujeito para outro significante. Assim, seFreud distinguia as psicoses das neuroses de transferência, isso deveria ser interpretado não como ausência de fenômenos transferenciais na psicose, mas de inviabilidade de gancho transferencial na psicose, isto é, como ausência da neurose de transferência na psicose. A transferência como um lugar, como um playground, seria viável somente nos casos em que o significante fosse ágil o suficiente para se deslocar e se movimentar nesse playground.

Essa diferenciação entre fenômeno transferencial egancho transferencial deve, portanto, ser observada através da escuta da fala do paciente. Essa escuta é realizada dia após dia, quando, o que se escuta depois, vai significar o que se escutou antes. Sem esquecer que as associações e imagens mentais daquele que escuta são tão importantes quanto o conteúdo daquilo que se escuta. 0 dispositivo do traço do caso e o quiasma da escuta psicanalítica conseguem integrar a escuta dos significantes encadeados na fal a do sujeito com as associações e imagens, formadas a partir deles, naquele que escuta. Escuta-se com os olhos na leitura do que se escuta e ouve-se o que se vê na leitura formada pelas próprias imagens mentais daquele que escuta.

Nosso método alia o percurso fenomenológico, próprio a um estudo de caso, ao percurso psicanalítico de construção do caso. Se, até agora, estudo e construção do caso pareciam mutuamente excludentes, as redações produzidas pelos estagiários mostraram que os dois métodos podem estar presentes em um mesmo texto.

Os tópicos propostos como guia para a redação do estudo de caso, ao incluírem o tópico sobre a posição transferencial, implicam o aluno na sua experiênciajunto aos pacientes. Observa-se, então, que o processo de escrita a partir dessa implicação gera um processo de introdução ao campo da escuta psicanalítica. Nesse sentido, o aluno aproxima-se metodologicamente da construção do caso praticada pelos psicanal istas.

Considere-se que nosso enfoque é a ressignificação, através da escrita, da experiênciajunto aos pacientes eque um trabalho de ressignificação da experiência supõe tradução e transposição da experiência através de diferentes perspectivas. Observa-se que, quanto mais aberto estiver o ângulo de visão, mais enriquecido se tornará o discurso para abordar essa experiência. No entanto, vale ressaltar 
que a condição para relatar um exame do estado mental não equivale à situação psíquica de escrever sobre a posição transferencial. Os diferentes tópicos do método de estudo e construção do caso corresponderiam, portanto, a distintos momentos da ressignificação da experiência junto aos pacientes.

Recebido em 2/ 3/ 2005. Aprovado em 12/ 5/ 2005.

\section{REFERÊNCIAS}

CAON, J. L. (1996) "Psicanálise <> Metapsicologia", in SLAVUTSKY, A.; BRITO e SOUSA, E. L.A (org.) História, clínica e perspectiva nos cem anos de Psicanálise, Porto Alegre: Artes Médicas, p.61-73.

DU MÉZIL, C. (1989) “Les rai sons d'un seminaire", in Letrait du cas. Paris: Point Hors Ligne.

FÉDIDA, P.(1991) "A construção do caso" in Nome, figura e memória. São Paulo: Escuta, p.215-236.

( 1996) 0 sítio do etrangeiro: a situação psicanalítica. São Paulo: Escuta.

FORBES, J. e FERRETI, C. “Entrevi stas preliminares e função diagnóstica nas neuroses e nas psicoses". Disponível na Internet em www.jorgeforbes.com.br/ . Acesso em 20 de fevereiro de 2005.

FOUCAULT, M. (1975/ 2004) Vigiar e punir, Petrópolis (RJ) : Vozes.

FREUD, S. ( 1987) GesammelteW erke. Frankfurt a. Main: Fischer.

FREUD, S. ( 1987) Edi ção standard brasileira das obras psicológicas completas deSigmund Freud. 2. ed. Rio de Janeiro: Imago.

(1914) "Recordar, repetir e elaborar", v. XII, p.191-203.

(1918[1914]) “História de uma neurose infantil”, v. XVII, p.13-151. (1911) "Notas psicanalíticas sobre um relato autobiográfico de um caso de paranóia (Dementia paranoides)", v. XII, p.15-108.

JAKOBSON, R. (1975) "Dois aspectos da linguagem e dois tipos de afasia”, in Lingüística e comunicação. São Paulo: Cultrix, p.34-62.

LACAN, J. (1953-1954/ 1979) Seminário livro 1, Os escritos técni cos deF reud. Rio de Janeiro: Jorge Zahar.

(1955-1956/ 1985). Seminário livro 3, As psicoses. Rio de Janeiro: Jorge Zahar.

(1998). Escritos. Rio de Janeiro: Jorge Zahar.

(1951) "Intervenção sobre a transferência”, p.214-225.

(1957) "A instância da letra no inconsciente ou a razão desde Freud", p.496-533.

(1960) "Subversão do sujeito e dialética do desejo", p. 807-842.

(2003). "Proposição de 9 de outubro de 1967 sobre o psicana-

lista da Escola", in Outros escritos. Rio de Janeiro: Jorge Zahar.

LECLAIRE, S. (1977) Psicanalisar. São Paulo: Perspectiva.

LÉVI-STRAUSS, C. (1955/ 1996) "A estrutura dos mitos", in Antropologia etrutural. Rio de Janeiro: Tempo Brasileiro, 5.ed., p.237-265. 
MAN N ONI, O. (1982) “La férule" in Ça n'empêchepas d'exister. Paris: Éditions du Seuil. p.65-84.

MASSON, J. F. (1986) A correspondência completa de Sigmund Freud para W ilhelm Fliess (1887-1904), Rio de Janeiro: Imago.

QUINET, A. (2001) . “Como se diagnostica hoje?”, in Psicanálisee Psiquiatria: controvérsias e convergências. Rio de Janeiro: Rios Ambiciosos, p.73-77.

TAFURI, M. I. (2003) Dos sons à palavra: explorações sobre o tratamento psicanalítico da criança autista. Brasília: Abrafipp.

TAUBER, B. (1989) “Um signifiant, un dispositif”, in DU MÉZIL, C. (org.). Le trait du cas, Paris: Point Hors Ligne, p.35-42.

M arta Regina de Leão D'Agord

mdagor@terra.com.br 